\title{
Control Estatal de Vendedores Callejeros en Río de Janeiro y en la Ciudad de Buenos Aires: Una Aproximación Comparativa a la Relación entre Vendedores y Agentes de Control ${ }^{1}$
}

State Control of Street Sellers in Rio de Janeiro and in the City of Buenos Aires: A Comparative Approach to the Relationship between Vendors and Control Agents

Controle Estatal de Vendedores Ambulantes no Rio De Janeiro e na Cidade de Buenos Aires: Uma Abordagem Comparativa da Relação entre Vendedores e Agentes de Controle

\section{Sofía Belcic}

Consejo Nacional de Investigaciones Científicas y Técnicas, Universidad de Buenos Aires, Buenos Aires, Argentina

\section{RESUMEN}

Este trabajo es resultado de una experiencia de trabajo de campo realizada entre vendedores callejeros (camelôs) en una zona del centro de la ciudad de Río de Janeiro (Brasil), producto de una instancia de intercambio de doctorado llevada adelante por la autora en dicha ciudad. El artículo indaga en los efectos que las prácticas de los agentes de la Guardia Municipal tienen sobre los camelôs de aquella zona, particularmente en las percepciones y las valoraciones que éstos tienen sobre las mismas, así como también en las reacciones y acciones de respuesta que despliegan. Asimismo, se establecen comparaciones con lo indagado respecto a las relaciones entre distintas agencias estatales y vendedores callejeros de la Ciudad de Buenos Aires (Argentina). Partiendo de las formas en las que los sujetos reaccionan y responden frente a las prácticas de control y represión de las agencias estatales que recaen sobre ellos,

1 La investigación contó con el apoyo de la beca de "Doutorado-Sanduíche Reverso" de la Fundação de Amparo à Pesquisa do Estado do Rio de Janeiro - FAPERJ. 
puntualmente, este trabajo se pregunta acerca de la legitimidad/ilegitimidad de las prácticas de los agentes estatales desde la perspectiva de los vendedores, enfocándose -aunque no exclusivamente- en lo que hace al uso de la fuerza por parte de los agentes. A partir de allí, el artículo busca, a su vez, aproximarse al modo en que los vendedores otorgan sentido a las actividades que realizan e indaga en laspercepciones sobre derechos que circulan entre los vendedores en cada uno de los espacios sociales analizados.

Palabras claves: Vendedores callejeros, Control estatal, Derechos, Violencia.

\section{ABSTRACT}

This work is the result of a field work experience carried out among street sellers in an area of the city center of Rio de Janeiro (Brazil), product of a PHD exchange carried out in that city. The article explores the effects of police agents practices with the street sellers, particularly perceptions and valuations that they have of them, as well as the reactions and response actions deployed. Likewise, I make a comparison between my field work in the City of Buenos Aires (Argentina) regarding the relationships between differents states agencies and streets sellers. Based on the ways in which the subjects react and respond to practices of control and repression of the state agencies that fall on them, specifically, this work asks about the legitimacy / illegitimacy of the practices of state agents from the seller's perspective, focusing -though not exclusively- on the use of force by agents. From there, seeks, at the same time, to approximate the way in which sellers give meaning to the activities they carry out and inquires about the perceptions of rights circulating between sellers in each of the social spaces analyzed.

Keyswords: Street sellers, State control, Rights, Violence.

\section{RESUMO}

Esse artigo é resultado de uma experiência de trabalho de campo realizada junto aos vendedores ambulantes (camelôs), na região central da cidade do Rio de Janeiro (Brasil), durante intercâmbio de doutorado realizado pela autora. O artigo tem como objetivo discutir os efeitos que as práticas dos agentes da Guarda Municipal têm sobre os vendedores ambulantes desta área, focando nas percepções e avaliações dos vendedores sobre essas práticas, assim como na maneira em que agem em resposta a elas. De modo complementar, o artigo também estabelece comparações com questões elaboradas previamente a respeito das vinculações entre diversos órgãos de regulação do uso do espaço público e vendedores ambulantes da cidade de Buenos Aires (Argentina). Com base na maneira pela qual os sujeitos reagem e respondem às práticas de controle e repressão dos órgãos do Estado a que estão submetidos, este trabalho discute a legitimidade/ilegitimidade das práticas dos agentes estatais de controle partindo da perspectiva dos vendedores, com enfoque no uso que os agentes fazem da força repressiva. A partir daí, o artigo procura, por sua vez, aproximar 
a maneira pela qual os vendedores ambulantes dão sentido às atividades que realizam e explorar as percepções do direito compartilhadas pelos vendedores em cada um dos espaços sociais analisados.

Palavras-chave: Vendedores ambulantes, Controle estatal, Direitos, Violência.

\section{INTRODUCCIÓN}

En una de mis habituales visitas a la Estação Central de Río de Janeiro, Ana, una vendedora de cincuenta años de edad y con dos años de experiencia de venta en la zona, me contó que días atrás un camelo $\hat{}^{2}$ había sido agredido por un agente de la Guardia Municipal ${ }^{3}$. El relato de Ana sería el primero de una serie de relatos que distintos camelôs me harían sobre lo sucedido. Reconstruyo el hecho según ellos me lo han contado.

Un lunes de enero a las 11 hs de la mañana, una camioneta Van de la Guardia Municipal ingresó a la UOP (Unidade de Ordem Pública) ubicada justo en frente de la Estação Central. Minutos después, la misma camioneta volvió a salir y al hacerlo, los agentes descendieron y comenzaron a caminar por la calle Praça Procópio Ferreira en dirección al portón principal de la estación. Los agentes de la Guardia pertenecían al grupo de los "boina preta"4, clasificación que los camelôs utilizan para identificar a quienes pertenecen al Grupamento de Operações

\footnotetext{
2 Retomando la definición de camelô del Diccionario Aurélio, refiere a un "Mercador que vende nas ruas, em general nas calçadas, bugigangas ou outros artigos, apregoando-os de modo típico" (PIRES, 2010, p. 324). La expresión camelô es la forma local de referirse a los vendedores ambulantes o de un punto fijo. Con esta palabra me referiré a los vendedores callejeros de Río de Janeiro a lo largo del escrito.

3 La Guardia Municipal de Río de Janeiro fue creada mediante la Ley Municipal no 1.887 del 27 de julio de 1992 y oficialmente implementada por el Decreto Municipal n ${ }^{\circ} 12.000$ del 30 de marzo de 1993, durante la intendencia de Cesar Maia. Como finalidad inicial de la Guardia el decreto determinaba, entre otras funciones, la "proteção de bens, serviços e instalações municipais do Rio de Janeiro, incluídos os de sua administração direta, indireta e fundacional". Años más tarde, a través del Decreto Municipal N 17931 del año 1999 se determinó a esta agencia como "responsável pela desobstrução dos bens públicos municipais, de forma a impedir a má utilização dos mesmos" y se la habilitó para "recolher mercadorias que estejam ocupando indevidamente os bens públicos municipais", pudiendo, de esta manera, proceder a la retención de las mercaderías de quienes se dedican a la venta en la vía pública sin licencias habilitantes.

4 Los camelôs hacen referencia al color de las boinas que visten los agentes. A diferencia de los "boina azul", agentes de la guardia que pertenecen al Grupamento Tático Móvel de la Guarda Municipal, los de "boina preta" son señalados por los camelôs como "bien malos" o "agresivos". Así, cuando identifican la llegada de los "boina preta", el estado de alerta es mayor porque consideran que hay probabilidades de que haya alguna situación de violencia. Un camelô me explicaba que "los boina preta son entrenados para golpear y los azules sólo para sacar la mercadería".
} 
Especiais (GOE) de la Guardia Municipal. Al verlos descender de la camioneta, los camelôs comenzaron a recoger su mercadería para alejarse rápidamente del lugar tan pronto como lograban levantar sus mantas y tableros. De resultas de esta intervención, un vendedor fue golpeado brutalmente en la cabeza con una cachiporra por parte de uno de los agentes de ese batalhão. Se trataba de Raphael, vendedor de no más de 30 años de edad, proveniente de Maranhão, que hacía seis meses que vendía junto a su esposa en la Estação Central. Siguiendo el relato de Raphael y el de los camelôs que vieron la situación, el agente lo golpeó justo en el momento en el que el vendedor se estaba retirando. El punto, según me contaron, es que Raphael demoró en salir porque retrocedió a ayudar a su esposa a levantar su mercadería y sus objetos personales. Pero los guardias se encontraban ya muy próximos a ella y cuando Raphael se agachó para recoger una mochila, uno de los guardias lo golpeó en la cabeza realizándole una herida que le implicaría luego seis puntos de sutura. Raphael me contó que no tuvo asistencia médica ni por parte de los agentes de la guardia, ni por parte de los agentes de "Centro Presente" que se encontraban en el lugar y a quienes recurrió para pedir ayuda dada la intensidad de su hemorragia. Cuando Raphael acudió a los mismos, le contestaron que "no podían hacer nada" y que ellos "no se metían". Fue por eso que tuvo que irse caminando junto a su esposa hacia un hospital en el cual le hicieron la sutura y le realizaron estudios para asegurarse que el golpe no comprometiera su cráneo.

Lo sucedido generó conmoción en el momento entre los camelôs que se encontraban en el lugar. Algunos de ellos les gritaban a los guardias mientras éstos los obligaban a tomar distancia protegiéndose con sus escudos y haciendo ademanes de golpes. "Ningún camelô está haciendo nada", "los agresivos son ustedes", eran algunas de las expresiones que se escuchaban entre los camelôs. El guardia que golpeó a Raphael se refugió rápidamente en una camioneta que, minutos más tarde, terminaría con un vidrio roto.

Raphael, luego de su visita al hospital, decidió dirigirse a una comisaría para hacer la denuncia. En la misma, los agentes de la Policía Civil se negaron a registrarla porque, según decían, estaban seguros que el guardia habría reaccionado a alguna agresión por parte de los camelôs ${ }^{7}$. Luego de algunas insistencias, finalmente el vendedor logró que le tomaran la denun-

5 Maranhão es una unidad federativa de la Región Nordeste de Brasil.

0 “Centro Presente" forma parte de la Operação Segurança Presente implementada desde 2014 y que funciona en distintas zonas de la ciudad. Dicha política es fruto de la cogestión del Governo do Estado y de un organismo privado, el Sistema Fecomércio RJ. Fuente: O que é a operação Centro Presente. (29 de agosto de 2016). Diário do Río de Janeiro. Recuperado de: https:/diariodorio.com/entenda-operacao-centro-presente/.

7 Esta situación de negarse a registrar la denuncia por parte de la Policía Civil ya fue caracterizada por Lenin Pires (2010) como un bloqueio policial al dar cuenta de lo difícil que era para los camelôs registrar situaciones de 
cia. Más tarde se contactó con un abogado conocido de un amigo suyo, con quien iniciaría una demanda penal. Según el camelô, se trataba de una "tentativa de homicidio" ya que el hecho de haberle golpeado en la cabeza y mientras él se encontraba agachado, hacía del asesinato una posibilidad. Eso es lo que buscaría demostrar junto con su abogado. Al momento de finalizar mi trabajo de campo en Río, sólo habían avanzado en la presentación de la demanda.

El hecho que describo sucedió en el tiempo en el que hice trabajo de campo ${ }^{8}$ en la zona de la Estação Central $^{9}$, e involucró a uno de los camelôs que cotidianamente vendía su mercadería allí y a un agente de la Guardia Municipal. Las explicaciones que los camelôs hicieron sobre lo sucedido resultaron reveladoras de sus valoraciones y percepciones sobre las prácticas de la Guardia Municipal de las cuales eran objeto, siendo esa la agencia que principalmente ejercía el control de la actividad de venta en la calle en ese lugar durante el periodo en el que realicé mi trabajo de campo. Asimismo, los relatos de mis interlocutores de aquel espacio social resultaron contrastantes con aquello que venía observando en mi trabajo de campo ${ }^{10}$ con vendedores callejeros del barrio de "Once" ${ }^{11}$ en la Ciudad de Buenos Aires.

Partiendo de aquellas indagaciones basadas en las formas en las que quienes se dedican a la actividad de venta callejera en un y otro lugar, reaccionan y responden frente a las prácticas

violencia y abuso estatal ante la policía. Además de la dificultad de que les registren la denuncia, Pires afirma que las versiones policiales deforman los hechos de modo que la acción violenta resulte justificada por la resistencia del vendedor a la autoridad que, según la norma, debe evitar la venta ambulante (PIRES, 2010, p. 317). En el caso aquí analizado vemos que la versión policial sobre los hechos también busca construir una justificación del uso de la fuerza como consecuencia de las supuestas acciones agresivas de los camelôs.

8 Este trabajo es resultado de parte de lo relevado durante un intercambio de doctorado que realicé en la ciudad de Río de Janeiro (Brasil) hacia mediados del año 2017 hasta principios del 2018. El mismo consistió en una estadía de seis meses como estudiante becaria del Programa de Pós-Graduação em Antropologia de la Universidade Federal Fluminense (PPGA/UFF). La beca Doutorado-Sanduíche Reverso que obtuve para la realización del intercambio, fue financiada por la Fundação de Amparo à Pesquisa do Estado do Rio de Janeiro - FAPERJ, bajo la dirección del Prof. Dr. Lenin dos Santos Pires y del Prof. Dr. Roberto Kant de Lima. La posibilidad de haber realizado esta instancia de intercambio fue fruto de una larga tradición de intercambio y discusión académica entre investigadores vinculados al Instituto de Estudos Comparados em Administração de Conflitos (INCT-InEAC) con sede en la Universidad Federal Fluminense, y del Equipo de Antropología Política y Jurídica (EAPJ) enraizado en la Sección Antropología Social del Instituto de Ciencias Antropológicas de la Facultad de Filosofía y Letras (UBA), del cual formo parte actualmente en mi carácter de becaria doctoral del CONICET (Consejo Nacional de Investigaciones Científicas y Técnicas).

9 Me refiero a las proximidades de la terminal ferroviaria "Estação Central do Brasil", ubicada en el centro de la ciudad de Río de Janeiro.

10 Se trata de mi investigación etnográfica aún en curso, la cual realizo en el marco de mi doctorado en Antropología (Facultad de Filosofía y Letras, UBA) bajo la dirección de la Dra. María Victoria Pita y la codirección de la Dra. Brenda Canelo.

11 El nombre oficial del barrio es Balvanera, sin embargo, el nombre de uso extendido es "Once" en alusión a la estación ferroviaria "Once de Septiembre" que se encuentra en la zona. 
de control y represión de las agencias estatales, en este trabajo puntualmente me pregunto acerca de la legitimidad/ilegitimidad de las prácticas de los agentes estatales desde la perspectiva de los vendedores, enfocándome -aunque no exclusivamente- en lo que hace al uso de la fuerza por parte de los agentes. A partir de allí, presento, a su vez, algunas aproximaciones sobre el modo en que los vendedores otorgan sentido a las actividades que realizan y a las percepciones sobre derechos que circulan en cada uno de los espacios sociales analizados.

Ahora bien, Gustavo Lins Ribeiro (1989) señala que el antropólogo, al no participar como nativo en las prácticas sociales de las poblaciones que estudia, experimenta, existencialmente, el "extrañamiento" como una unidad contradictoria: al ser, al mismo tiempo, "aproximación y distanciamiento". "Es como estar delante de un sistema de signos-vivirlo relacionándose primeramente con sus significantes pero sin comprender del todo sus significados" (RIBEIRO, 1989, p. 66). Esta experiencia, propia de la investigación etnográfica, se vio exacerbada durante mi trabajo de campo en Río de Janeiro por encontrarme en una ciudad desconocida para mí. Así, la experiencia de hacer trabajo de campo allí fue más que indagar en el "mundo" de los camelôs y sus relaciones, ya que implicó que además adentrara en un idioma, en códigos, en formas de organización social y configuraciones espaciales más amplias que me eran ajenas ${ }^{12}$. De aquí la sensación de que, sobre todo al inicio de mi trabajo de campo, lo distante primara por sobre lo próximo, requiriendo en mí un mayor esfuerzo consciente de familiarizar aquello que resultaba "exótico" (RIBEIRO, 1989). Pero al mismo tiempo esta sensación convivía con otra, ya que mi propia experiencia de trabajo de campo con los vendedores porteños hacía que el "mundo" distante de los camelôs se volviera rápidamente próximo. Así, encontraba que tanto semejanzas como contrastes entre ambos espacios sociales surgían constantemente y casi de manera espontánea en mis reflexiones durante el trabajo de campo.

De aquí que la posibilidad de "extrañamiento" me haya permitido repensar ciertas cuestiones del universo de los vendedores con los que trabajo en la Ciudad de Buenos Aires y que se esclarecieron (o más bien, se complejizaron) ante el contraste que significó mi experiencia con los camelôs de la ciudad de Río de Janeiro. Valores y obligaciones morales en las relaciones establecidas con los agentes de control, percepciones de los vendedores sobre su identidad y derechos, son algunos de los aspectos que resultaron contrastantes y que abordo en este artículo.

12 Como forma de acercamiento a estos aspectos, me resultó muy provechoso haber realizado una primera etapa de trabajo de campo exploratoria por distintos puntos de la ciudad durante los dos meses previos a mi adentramiento a Estação Central. 


\section{BREVE DESCRIPCIÓN DEL ESPACIO}

La Estação Central se encuentra ubicada en el barrio "Centro" de Río de Janeiro, en la zona central de la ciudad. Allí convergen dos terminales de ómnibus, una estación de ferrocarril y una de las estaciones de metrô; siendo éste un lugar de importante circulación cotidiana de personas. Fueron cuatro meses de trabajo de campo en ese lugar en los que realicé observaciones con registro, generé "situaciones conversacionales" (PITA y PACECCA, 2017, p. 54) con los camelôs y realicé entrevistas semiestructuradas a los mismos. Mi intención era entender parte del cotidiano específico de ese lugar, concentrándome especialmente en las relaciones que los camelôs establecían con las agencias que controlaban su actividad ${ }^{13}$.

Frente a la Estação Central se encuentra la Praça Procópio Ferreira. En esa plaza de asfalto funciona la feria "Centro Comercial Popular da Praça Procópio Ferreira", la cual cuenta con aproximadamente cincuenta barracas $^{14}$. Antiguamente, en el mismo lugar, funcionaba un camelódromo $^{15}$ de mayores dimensiones, pero en el año 2005 (tras la instalación de la Secretária de Estado de Segurança Pública en el predio de la Estação Central), la Prefectura, siguiendo indicaciones del secretario de Segurança Pública, "limpió" los alrededores de la sede de la secretaría desalojando las instalaciones del camelódromo (PIRES, 2010, p. 337). En aquel momento, los camelôs desalojados fueron trasladados contra su voluntad a diferentes puntos de la ciudad. Un tiempo después, según me contaron camelôs de la feria, tras distintas negociaciones con autoridades de la Prefectura, algunos de los antiguos camelôs lograron volver a la plaza y conformaron el centro comercial que hoy se encuentra en funcionamiento.

Mis primeras indagaciones en la zona comenzaron por la feria de la Praça Procópio Fer-

\footnotetext{
13 El trabajo de campo localizado estuvo, además, acompañado, durante los seis meses de estadía, de entrevistas a actores con intervención y/o con profundo conocimiento sobre la organización de la actividad de venta callejera y del seguimiento continuo de las fuentes secundarias como el rastreo de noticias en diarios digitales vinculadas a acontecimientos que involucraran a camelôs, así como también de la normativa que regula la venta ambulante en la ciudad de Río de Janeiro.

14 Barraca es el nombre que reciben las estructuras metálicas en las cuales los vendedores exhiben sus mercaderías para la venta. Quienes se encuentran regularizados en un punto fijo, mayoritariamente, exponen sus mercaderías usando las mismas, las cuales deben cumplir con una serie de parámetros estipulados por la Prefectura. Las dimensiones que deben tener las barracas, los colores de las lonas que las recubren definidos según el barrio en el que se ubican, las distancias entre barracas, son algunos de esos parámetros.

15 El término refiere a espacios delimitados para el ejercicio de la venta con concentración de barracas. Según señala Pires, el ejecutivo municipal carioca tiene una lógica histórica de desterritorialización de la venta ambulante en la ciudad, reterritorializándola en espacios delimitados en base a lógicas de utilización y pertenencias extrañas a los segmentos que se ocupan de aquella actividad (PIRES, 2010, p. 328).
} 
reira, donde pude observar que algunos de los camelôs que allí vendían también lo hacían en la calle. En esta última, se concentraban mayoritariamente en un sector específico; en la vereda del Portão 1 de la Estação Central, portón principal de la estación. Allí, los camelôs, junto a otros que solamente vendían en la calle, se distribuían en la vereda formando dos hileras con mantas o tableros en los que exponían la mercadería, a modo de dejar un "sendero" entre ambas hileras para que circularan las personas que entraban y salían de la estación. Quienes vendían en ese espacio lo hacían sin contar con licencias otorgadas por la Prefectura ${ }^{16}$.

En frente del Portão 1, calle por medio, se emplaza la Unidade de Ordem Pública “UOP-Centro" perteneciente a la Guardia Municipal. La disposición espacial de la misma posibilitaba que fuera permanentemente observada por los camelôs que vendían en el portón principal, quienes se mantenían atentos a los movimientos de las camionetas Van de la Guardia Municipal que entraban y salían constantemente de la UOP, de manera de poder anticipar una posible intervención.

\section{DE LOS "ACUERDOS" Y SUS RUPTURAS}

Las explicaciones que los camelôs hicieron sobre el hecho que da comienzo a este artículo me permitió profundizar en dos cuestiones en las que me detendré en lo que sigue. Por un lado, en las dinámicas de interacción entre guardias y camelôs, y cómo era entendido el "golpe" dentro de las mismas. Por el otro, y a partir de lo anterior, en el lugar que ocupaba la violencia en estas relaciones. Particularmente, la manera en la que los vendedores percibían el uso de la fuerza por parte de los agentes y la legitimidad/ilegitimidad del mismo desde su perspectiva.

Quienes me contaron acerca de la agresión del guardia al camelô, insistían en que el vendedor "estaba saliendo" en el momento en el que fue golpeado. Es que "salir" cuando llegaban los guardias era lo esperado ante estas situaciones. Así es como lo describían los camelôs y así lo observé durante el período en que hice trabajo de campo allí.

Una tarde posterior al hecho del golpe pude observar la dinámica establecida entre guardias y camelôs. Al momento en el que los guardias descendían de la camioneta Van, los camelôs -que se encontraban siempre expectantes- guardaban rápidamente la mercadería, levantaban

16 Me refiero a las habilitaciones formales para ejercer la actividad de venta que otorga la Prefectura a través de la Coordenadoria de Licenciamento e Fiscalização dependiente de la Secretária de Fazenda. 
sus mantas y se alejaban velozmente por el lado contrario al que avanzaban los guardias. Estos se desplazaban por la vereda, caminando a un ritmo que daba tiempo suficiente para que los camelôs juntaran sus cosas y se retiraran, si lo hacían rápidamente.

Ahora bien, no era sólo en ese momento en el que los camelôs debían levantar su mercadería. El hecho de estar ubicados justo enfrente de la UOP hacía del Portão 1 un lugar de paso para agentes que ingresaban y salían de aquella. Así, cuando algún agente pasaba, incluso sin que tuviera la intención de realizar un operativo, los camelôs igualmente "debían levantar" la mercadería. Thiago, vendedor con nueve años de experiencia en Estação Central, me explicaba:

"Cuando ellos salen de ahí adentro (señala la UOP), pasan por aquí y ahí la gente tiene que respetar también. Recogemos, sacamos las cosas, ahí ellos pasan... y después volvemos".

Los camelôs señalaban hacerlo por "respeto". Es decir, levantar las cosas cuando pasaban los guardias era lo esperado en tanto implicaba una demostración de respeto para con ellos. Rose, vendedora con más de treinta años de experiencia de venta en la calle, explicaba:

"Cuando vienen los guardias las personas se van, todo el mundo sabe que tiene que salir. Ellos (los guardias) pasan... (imita la voz de un guardia) 'Yo tengo autoridad, yo estoy pasando, que salga todo el mundo. Si continúan, yo llevo"".

En la investigación de Lenin Pires (2005) sobre camelôs de trenes y vigilantes, el autor daba cuenta de aquellos "acuerdos tácitos" que se establecían entre unos y otros, donde las prácticas de disimulo y discreción por parte de los camelôs eran la forma de evitar la represión cuando intervenía un agente. Aquel disimulo, antes que buscar que el vigilante no se diera cuenta de que la persona estaba vendiendo, consistía más bien en realizar una buena actuación ante sus ojos que no diera lugar a interpretar ninguna acción como una falta de "respeto" que desmoralizara su autoridad. Si así lo fuera, el vigilante castigaría al vendedor sea aplicando el derrame o, en ocasiones, el esculacho. Por el contrario, una buena actuación por parte del camelô funcionaría, entonces, como una demostración de respeto frente a la cual el vigilante tendría a cambio "consideración" por la situación social del camelô y le dejaría seguir viaje (PIRES, 2005, p. 132).

El análisis de Pires me resulta útil para reflexionar sobre aquello que observé entre camelôs y guardias en Estação Central. Analizando las dinámicas de interacción entre los mismos era posible ver que allí también existía un "acuerdo tácito". Entre las acciones esperadas de unos y otros, existían además tiempos pautados. Los camelôs debían realizar su huida con rapidez ante 
la presencia de los guardias evitando la cercanía corporal con los mismos. Así, Thiago indicaba:

"Hay que tener experiencia en la calle; el que no tiene experiencia... (no concluye la oración) Cuando viene el guardia, hay que salir corriendo".

“Huir", es decir, irse de la manera más rápida posible, parecía ser un aspecto importante de la respuesta esperable, de aquí que los camelôs señalaran que la demora en salir fue lo que provocó el golpe que recibió Raphael. Así lo explicaba Raphael:

"Ellos (los guardias) vinieron de allá (señala la UOP). Ahí yo levanté mi carro rápido. Y mi esposa quedó media atrapada, entonces fui a ayudarla a ella, rápido, porque yo ya había recogido mi carro así que la ayudé a ella. Y cuando la fui a ayudar a ella, yo ya estaba saliendo, vinieron atrás mío y les dije 'Calma, que ya estoy saliendo'. Ahí metieron la mano en el carro, comenzaron a tirar y robaron la mercadería de ella. Y cuando me agaché para agarrar la mochila, ahí me dio una porrada ${ }^{17}$ ".

Retomando el planteo de Pires (2005), es posible pensar que en este caso la demora en salir haya sido interpretada por el guardia como una falta de respeto. En esta línea, el golpe se trataría, entonces, de una acción disciplinadora por parte del guardia en la búsqueda de reafirmar su autoridad, la cual parecía desmoralizarse frente a la mala actuación del vendedor (PIRES, 2005, p. 131). Ahora bien, desde la mirada de los camelôs, aunque el vendedor se haya demorado, aquel golpe resultó injustificable. El golpe no parecía ser parte de las acciones esperadas o por lo menos, toleradas, ante esta situación. Según los camelôs, el guardia debería haber considerado la demora o, en todo caso, quitado la mercadería, acción que suelen esperar si se encuentran distraídos o si no son veloces al emprender la retirada.

De ahí la reacción y la conmoción que provocó el hecho en el momento. Y de ahí también el sentimiento de indignación que expresaban los camelôs en sus relatos, el cual revelaba la ilegitimidad del golpe desde su perspectiva. Por otra parte, el hecho de que el guardia haya huido tras lo acontecido también estaría dando cuenta de cierta falta de adecuación de su comportamiento a lo establecido en aquel espacio social ${ }^{18}$.

En la investigación ya citada con vendedores de trenes, Pires (2005) dio cuenta de la categoría de esculacho como un aspecto de las dinámicas de interacción entre vigilantes de tre-

17 El término porrada refiere a una agresión física, a un golpe fuerte.

18 Hasta mi regreso a Buenos Aires, los camelôs aún no habían visto volver al guardia que había agredido a Raphael aunque sí a quienes solían trabajar con él en el mismo batalhão. Uno de los camelôs me señalaba que esto se debía a la posibilidad de venganza que podía surgir entre los camelôs tras lo sucedido. 
nes y camelôs. Mientras que el derrame ${ }^{19}$ parecía constituirse como una sanción a los desvíos de los camelôs delante de las reglas establecidas tácitamente entre los diferentes actores que compartían aquel espacio social (PIRES, 2005, p. 134), el esculacho, forma de relacionamiento violento tanto físico como moral, se trataba de una humillación que indignaba a los camelôs ( $\mathrm{p}$. 136). Así, el esculacho parecía representar un nivel de "desconsideración" que imposibilitaba la manutención del orden vigente, mismo que éste ya fuese estructurado de forma desigual; era un procedimiento que peligraba expulsar a la víctima por fuera de la escala aceptable de aquél cotidiano jerarquizado (p. 152). A diferencia del derrame -que sin bien era una práctica igualmente no autorizada en términos legales era calificada como legítima por el segmento que sufría sus efectos (p. 134)- el esculacho "soava como uma denúncia grave, uma desconsideração singular" (p. 152).

Retomar la definición de esculacho para pensar el hecho aquí analizado, me permite enfatizar la ilegitimidad de la acción del guardia, ya que se ubicaba por fuera de las acciones esperadas por parte de los camelôs. Si bien durante mi trabajo de campo, no identifiqué en los relatos de mis interlocutores el término literal esculacho, creo que la ilegitimidad de la acción se encarnó en otra categoría a la que se refirieron mis interlocutores, la de covardía. Señalaba Raphael:

" $\mathrm{R}$ : Cuando ellos vienen todo el mundo se va, nadie hace reacción alguna. Nadie pelea, todo el mundo sale.

E: ¿Y vos te demoraste para ayudar a tu esposa?

R: Sí, volví para ayudarla a ella. Y ahí sucedió ese hecho, esa covardía, porque eso se llama covardía".

En otra ocasión, Thiago sostenía:

"Fue una covardía, el no reaccionó ni nada, fue a agarrar el documento de ella. Hasta el documento de ella se llevó. Cuando él bajó a agarrar la cartera, ¡pá! (sonido de golpe) Covardía, una pura covardía”.

En un principio no me resultaba sencillo comprender a qué se referían los camelôs cuando calificaban la situación como una covardía. Me parecía que encerraba otro significado distinto a la falta de coraje o de valentía a la que a mí me remitía el término. Pensando y conversando con personas cariocas, más adelante entendí que la categoría podía estar teniendo un plus de

19 El derrame refería a cuando los vigilantes tomaban la mercadería de los camelôs. 
significado. Consideré, entonces, que la covardía a la que se referían los camelôs era expresión de una relación de desigualdad en tanto la acción era entendida como el abuso de alguien que ya se encontraba "de por sí” en una situación de ventaja frente a un otro más débil20. Así interpreté que el guardia, sujeto estructuralmente ubicado en una posición de superioridad, por medio del golpe reforzaba de manera abusiva el lugar que ocupaba frente al vendedor, sujeto más débil en términos de las relaciones sociales implicadas.

En esta línea, la acusación de covardía puede ser entendida como la expresión del sentimiento de indignación que produjo entre los camelôs la falta de consideración por parte del guardia, quien "não bastando submeter o oponente a tais regras, se fazia necessário, via de regra, humilhá-lo" (PIRES, 2005, p. 152). En este sentido, es posible pensar la acción del vigilante como un "insulto moral” en términos de Luís R. Cardoso de Oliveira (2004; 2004a; 2005). El autor señala que el "insulto moral” realza dos características principales: "trata-se de uma agressão objetiva a direitos que não pode ser adequadamente traduzida em evidências materiais; e, sempre implica uma desvalorização ou negação da identidade do outro" (CARDOSO DE OLIVEIRA, 2005, p. 2). Así, el "insulto aparece então como uma agressão à dignidade da vítima, ou como a negação de uma obrigação moral que, pelo menos em certos casos, significa um desrespeito a direitos que demandam respaldo institucional" (p. 4). Las expresiones de los camelôs dan cuenta de la agresión moral, además de la física, que significó el golpe recibido por Raphael. La expresión de covardía puede ser leída, en este sentido, como la manifestación del sentimiento de indignación de quien vive la experiencia del insulto; como la valoración que expresa la negación de una obligación moral entre los actores implicados en ese espacio social.

\section{LA LEGITIMIDAD/ILEGITIMIDAD DE LA VIOLENCIA}

Si bien, como di cuenta en el apartado anterior, lo sucedido generaba indignación entre los camelôs, hay un aspecto de las expresiones que me llamó particularmente la atención y es que los camelôs enfatizaran que el vendedor "no había hecho nada". El mismo Raphael aclara-

20 Según la definición del Dicionário online de Português, covardía refiere al "Comportamento que expressa falta de coragem; gesto caracterizado pelo medo ou temor; que não é ousado: pusilâmine", o bien, "Violência efetuada contra uma pessoa mais fraca: o que o pai fez com o filho foi uma covardia" (Dicionário online de Português. Significado de Covardia. Recuperado de https://www.dicio.com.br/covardia/). A diferencia del idioma español, la "covardía" como sustantivo puede ser una acción hecha por alguien, de allí la posibilidad de la expresión en el portugués "ele fiz uma covardia". 
ba: "En ningún momento intenté ser agresivo con él, en ningún momento. No hice nada".

¿Por qué los camelôs constantemente realizaban esta aclaración? ¿Habría otras situaciones en las que la violencia sí resultara esperada? En lo personal, lo que a mí me indignaba era el golpe, independientemente de las acciones que hubiera realizado el vendedor. Pero alejándome de mi propia indignación, me di cuenta que lo que en verdad me asombraba era el contraste que encontraba con las reacciones que estaba acostumbrada a observar entre los vendedores de la Ciudad de Buenos Aires.

Entendí que entre los camelôs, la violencia física por parte de los agentes que se encargaban de su control, era una posibilidad en ciertas situaciones. En caso de que los camelôs se rehusaran a irse o ejercieran alguna resistencia ante la incautación de mercadería, podían encontrarse con una respuesta que implicara violencia física. De aquí las continuas aclaraciones que los camelôs hacían indicando que Raphael "no hizo nada", como si "hacer algo" conllevara el uso de la fuerza como una forma posible de respuesta por parte de los agentes. Asimismo, expresiones como la de un camelô cuando me dijo: "Por eso no enfrento, porque yo no voy a perder la vida por eso. Me voy, salgo corriendo", dejan entrever que la violencia extrema era una posibilidad en estas relaciones. Incluso más, luego de aquella frase, el mismo vendedor me contó el caso de un conocido suyo que hacía algunos años había muerto por una herida mal curada tiempo después de haber recibido un golpe en la cabeza durante un operativo.

Considero que las explicaciones de los camelôs, dan cuenta de cierta legitimidad del uso de la fuerza en determinadas situaciones, en aquellas en que los camelôs ejerzan resistencia. Es decir, siguiendo las expresiones de los camelôs, lo ilegítimo del golpe analizado en este escrito, lo que lo convirtió en un esculacho, fue la ausencia de resistencia por parte del vendedor. Lo impugnado resultó ser la falta de consideración por parte del guardia frente a una situación en la que los vendedores entienden que no había habido falta de respeto hacia la autoridad. En esta línea, la acusación de covardia expresaba la violación a los códigos establecidos entre los vendedores y los guardias. En contraposición a esto, en aquellas situaciones en las que los camelôs se resistieran frente a la autoridad de los guardias, es cuando el ejercicio de la violencia se convertía en una posibilidad incluso legítima desde el punto de vista de los vendedores, según el orden establecido en ese espacio social.

Esta legitimidad parece ser compartida, además, con otros actores, tal como se desprende del relato de Raphael cuando me contó que un programa de radio había reproducido la noticia del hecho diciendo que "un guardia agredió a un vendedor sin necesidad, sin motivo alguno"; o bien, en el momento en el que realizó la denuncia y el policía que lo recibió intentó justificar la acción del guardia reconstruyendo una versión oficial en la que los vendedores ha- 
brían comenzado un enfrentamiento durante el operativo de la Guardia.

Ahora bien, las reacciones frente al uso de la fuerza que encontré entre los camelôs me permitieron repensar mis interpretaciones acerca de las prácticas y percepciones de los vendedores de la Ciudad de Buenos Aires. Cuando comencé a realizar mi trabajo de campo en el barrio de "Once" en el año 2014, los vendedores se relacionaban cotidianamente en las calles con agentes de la Policía Federal. Tal como lo han señalado diversas etnografías (PIRES, 2010; PITA; PACECCA, 2017) y como he podido indagar en mi investigación, los vendedores porteños establecían con los agentes policiales negociaciones que les posibilitaban desarrollar su actividad. En términos de María Victoria Pita (2017), los agentes forzaban ciertos "arreglos" bajo los cuales los vendedores podían negociar continuar ejerciendo la venta y evitar de esa manera la aplicación de la ley -que funcionaba como objeto de negociación-, las más de las veces, bajo amenaza de violencia física y/o moral (PITA, 2017, p. 150). Si bien los "arreglos" se establecían con cuotas diferenciales de poder y suponían coacción por parte de los agentes, buscaban algún tipo de acuerdo "combinado entre las partes" (p. 150). En mi indagación en “Once", encontraba en aquél entonces que estas negociaciones podían exigir pedidos de dinero o de mercadería, o bien podían consistir en establecer acuerdos de los más variados, tales como definir horarios y lugares en los que se podía ejercer la actividad. Para los vendedores, esto les significaba un relativo marco de previsibilidad bajo el cual podían desarrollar su actividad, más no sea dentro de una frágil estabilidad (tal como lo demostrarán los sucesos de los años siguientes). De aquí que la intervención de novedosas agencias, como la de la Policía Metropolitana y de los inspectores de Espacio Público ${ }^{21}$, haya resultado disruptiva de aquella relativa estabilidad sostenida en base a "acuerdos". Esto porque las intervenciones de las nuevas agencias implicaban que los vendedores necesariamente debieran interrumpir su actividad, por lo menos durante el tiempo en que duraban los operativos ${ }^{22}$. Eludiendo a los agentes es como veía en aquél entonces que los vendedores evitaban las incautaciones de mercadería y, también, las situaciones de

21 Mientras que la primera refiere a una agencia policial dependiente del Ministerio de Seguridad porteño (actualmente fusionada en la Policía de la Ciudad), los últimos corresponden a un cuerpo civil con poder de policía dependiente del Ministerio de Ambiente y Espacio Público del Gobierno de la Ciudad de Buenos Aires.

22 Las intervenciones de estas dos agencias se realizaban de manera simultánea y por períodos de tiempo determinados. Es decir, había momentos o hasta incluso días consecutivos en los que estas agencias aparecían en la zona aplicando contravenciones y faltas, e incautando la mercadería de quienes permanecieran realizando la venta. Estos procedimientos podían implicar violencia física como forcejeos y empujones, así como también insultos verbales; o grandes despliegues de violencia cuando se trataba de desalojos masivos, tales como el llevado a cabo el 29 de enero de 2014. Para más información sobre este último hecho, consultar el capítulo PACECCA, María Inés; CANELO, Brenda; BELCIC, Sofía. Culpar a los negros y a los pobres. Los "manteros" senegaleses ante los allanamientos en el barrio de Once. In: PITA, María Victoria y PACECCA, María Inés (eds.), Territorios de control policial. Gestión de ilegalismos en la Ciudad de Buenos Aires. Buenos Aires: Editorial de la FFyL-UBA, 2017. 
violencia física que podían derivar de estas intervenciones.

Las prácticas de control y de represión se intensificaron aun más con la reciente creación e intervención de la Policía de la Ciudad $^{23}$, a la vez que se volvieron cotidianas para los vendedores. En la zona de “Once”, agentes de la misma junto a inspectores de Espacio Público realizan operativos día tras día en los que incautan mercadería de los vendedores además de ejercer, en reiteradas ocasiones, violencia física sobre los mismos. Aquellas intervenciones pueden devenir, además, en detenciones, las más de las veces justificadas por los agentes bajo las figuras de "Atentado" o "Resistencia a la Autoridad".

En este contexto, durante mi trabajo de campo, he visto cómo los vendedores se indignan y reaccionan frente al uso de la fuerza por parte de estas agencias. Y aquí una diferencia, lo hacen independientemente de la actitud que haya tenido el vendedor víctima de la misma. Es decir, incluso en los casos en los que haya habido alguna resistencia del vendedor ante un operativo, no justifican la agresión física por parte del agente policial. Si bien son recurrentes las situaciones en las que se ejerce violencia hacia los vendedores, resulta ilustrativo el caso de un vendedor senegalés del barrio de Constitución, que, al resistirse a entregarle su mercadería a un agente de la Policía de la Ciudad, éste lo redujo agarrándolo del cuello hasta producirle una asfixia que provocó su desmayo. Los vendedores con los que hablé en aquella ocasión se mostraban indignados frente al hecho e incluso justificaban la resistencia del vendedor ya que se había negado a entregar la mercadería porque "necesitaba trabajar". El hecho circuló por los medios de comunicación y el caso hasta fue presentado ante la Comisión Interamericana de Derechos Humanos por organizaciones defensoras de los derechos humanos como una muestra de la vulneración de derechos que estaban atravesando las personas migrantes en la Argentina. Así, independientemente de las reacciones del vendedor, distintos actores coincidieron en la ilegitimidad del uso de la fuerza por parte del agente policial frente al vendedor callejero.

Más allá del hecho sucedido en Estação Central analizado en este trabajo, las diferencias entre las reacciones y valoraciones de los vendedores porteños y las de los camelôs, ya eran visibles ante otras prácticas de las agencias, incluso ante aquellas que no implicaban violencia física. En una de mis visitas a la Estação Central, presencié una intervención de agentes de la

23 El 17 de noviembre de 2016 se sancionó la Ley de Seguridad integral 5688/16, que entró en vigencia el 2 de enero de 2017. Esta ley estableció el traspaso de los agentes de la Policía Federal destacados en la ciudad a la órbita del Gobierno de la Ciudad de Buenos Aires, creando de ese modo la Policía de la Ciudad. Ello conllevó la fusión de diecinueve mil efectivos de la Policía Federal y seis mil de la Policía Metropolitana. El operativo de desalojo de los vendedores de las calles de "Once”, realizado a pocos días del inicio del ejercicio de la Policía de la Ciudad, fue una de las primeras acciones que encabezó esta nueva agencia policial. A partir de allí, los vendedores comenzaron a ser controlados en las calles por los agentes de la nueva policía, quienes desde entonces realizan operativos junto a los inspectores de Espacio Público. 
Guardia Municipal que implicó que los camelôs tuvieran que levantar rápidamente la mercadería para, minutos después, volver a ubicarse en el mismo lugar una vez que aquellos se retiraron. Luego de haber regresado a "su lugar" y conversando sobre lo sucedido, un vendedor me dijo con resignación: "la vida del camelô es así”. Esta expresión da cuenta de cierta sumisión del camelô a las dinámicas establecidas con los guardias, de una incorporación de las condiciones a las que debe someterse un camelô. Por contraste, los vendedores porteños reaccionan con indignación al tener que interrumpir constantemente la venta ante la presencia policial. Los vendedores se quejan por el estado de "alerta permanente" en el que se encuentran ya que deben "salir corriendo" ante la presencia de los agentes. Frente a esto remarcan frecuentemente sentirse tratados como "delincuentes". Dicha clasificación da cuenta de la agresión de orden moral que les provoca ser objeto de ese tipo de prácticas. Esta forma de percibirse, al encontrarse huyendo permanentemente de la persecución policial, contrasta notoriamente con aquella expresión que postula "la vida del camelô es así" la cual deja entrever cierta resignación entre los camelôs.

\section{IDENTIDADES Y DERECHOS}

La diferencia en encontrar entre los camelôs mayor sumisión e incluso, en ocasiones, legitimación de ciertas prácticas que entre los vendedores porteños producen indignación, puede ser pensada en vinculación con las percepciones sobre su identidad y derechos que circulan entre quienes se dedican a la misma actividad en cada uno de los espacios sociales indagados.

Así, entre los vendedores porteños, el percibirse tratados como "delincuentes" ante la persecución policial, es expresión de la sensación de humillación que les produce la desvaloración de su identidad al no verse reconocidos como "trabajadores".

La apelación a la identidad de "trabajador" entre los vendedores porteños me permite reflexionar sobre el valor que adquiere la actividad concebida bajo estos términos. Por un lado, es posible relacionarla con ideas sobre el "trabajo" que circulan en el imaginario social de la sociedad argentina como forma legítima de integración social (PERELMAN, 2011; 2013). En el devenir de procesos históricos atravesados en el país, el acceso al mercado de trabajo formal se ha constituido como una forma legítima de acceder a la reproducción social (DANANI y GRASSI 2008, apud PERELMAN, 2013, p. 242). Ahora bien, Mariano Perelman (2011) señala:

Si por varias décadas del siglo XX el mercado de trabajo formal logró incluir parte importante de la población activa, a partir de la década de 1970, los 
cambios en el modelo productivo, la implementación de políticas de corte neoliberal generaron fuertes reacomodamientos en la estructura social argentina. Con un mercado de trabajo en claro retroceso, miles de personas fueron quedando desocupadas en el mercado formal y tuvieron que buscar formas alternativas para obtener los medios de vida (PERELMAN, 2011, p. $71)$.

Si bien la expansión de actividades informales no impidió que aquella idea sobre el "trabajo" siga operando con fuerza en el imaginario social, la misma es permanentemente resignificada por quienes quedaron desocupadas en el mercado formal y tuvieron que buscar formas alternativas para obtener medios de vida. En esta línea, las investigaciones de Perelman (2011, 2013, 2017) sobre vendedores ambulantes de trenes y recolectores informales de la Ciudad de Buenos Aires, revelaron cómo determinados grupos dedicados a aquellas actividades apelaban a su identidad de "trabajadores", escapando, de esta manera, a otras etiquetas, tales como las de "pobre vergonzante" en el caso de los vendedores de trenes (PERELMAN, 2013, p. 242). En este sentido, en mi trabajo de campo, encuentro que los vendedores porteños refuerzan su identidad de "trabajadores" y, en este caso, lo hacen en contraposición a otras categorías tales como las de "delincuentes". De esa manera, los vendedores realzan su actividad como un modo legítimo de ganarse la vida; a la vez que apelan a la condición de ser personas moralmente "dignas" (CARDOSO DE OLIVEIRA, 2004; 2004a; 2005).

María Inés Fernández Álvarez (2007) analizó la asociación entre trabajo y dignidad a partir del caso de los trabajadores de una fábrica recuperada, en donde el sentido otorgado al trabajo hacía de la actividad que realizaban no sólo una forma de garantizar su supervivencia sino también una fuente de dignidad. La autora señala que estas dimensiones de sentido se plasmaban en la forma en la que los trabajadores desplegaban sus acciones de demanda por "trabajo genuino" en la defensa de sus puestos de trabajo, significando tanto una lucha por la "supervivencia” como una lucha por la “dignidad” (FERNÁNDEZ ÁLVAREZ, 2007, p. 4). Considerando este análisis, de manera similar a los trabajadores de aquella fábrica, a partir de sus acciones los vendedores callejeros no sólo defienden su fuente de subsistencia sino también su dignidad en tanto "trabajadores". De aquí la humillación tras sentirse tratados como "delincuentes" por los agentes policiales; expresión que da cuenta del "daño moral" (CARDOSO DE OLIVEIRA, 2004; 2004a; 2005), de la ofensa a la dignidad que les produce ciertas formas de tratamiento, las cuales son percibidas como una falta de reconocimiento en su condición de "trabajadores".

Entonces, es a partir de la identificación de su actividad como un "trabajo", en tanto forma digna y legítima de ganarse la vida, que los vendedores defienden su actividad, a la vez que impugnan formas de tratamiento que no consideran adecuadas. Es en su "derecho a trabajar" 
que los vendedores reaccionan y se movilizan, tras la indignación que les produce ciertos tratos concebidos como intolerables en tanto "trabajadores". Ahora bien, señala Perelman (2017) la importancia de atender a las temporalidades de los procesos sociales a la hora de analizar las subjetividades y las estrategias de quienes construyen "formas de ganarse la vida". "Las diferentes temporalidades de los procesos sociales son centrales en los modos en que las personas calculan lo que es una vida digna y transforman los marcos de referencia y las condiciones de posibilidad de acción" (PERELMAN, 2017, p. 93). En este sentido, considero que las recientes formas de tratamiento de las agencias estatales de la ciudad, que incluyeron prácticas cada vez más represivas y persecutorias hacia quienes realizan su actividad en la calle, produjeron modificaciones no sólo en las estrategias que los mismos despliegan para poder seguir desarrollando su actividad, sino en las valoraciones que los vendedores hacen sobre su actividad y en la posibilidad de concebirse como sujetos de derechos. Es en el marco de esos procesos represivos, en el cual la identidad de "trabajador" emerge como una categoría cada vez más aglutinadora entre vendedores que ejercen la actividad, como mis interlocutores porteños a quienes me refiero en este trabajo. Es posible pensar estos devenires como procesos de subjetivación política (FASSIN, 2013) en los que, partiendo del reconocimiento de su actividad como un "trabajo", los vendedores la defienden en tanto un "derecho". La intensificación de los tratamientos represivos conlleva así una "respuesta a lo que se experimenta o se imagina como una injuria o como una injusticia" (FASSIN, 2013, p. 249), es decir, la indignación propia de la falta de reconocimiento en tanto "trabajadores". Es a partir de estos procesos que los vendedores reaccionan y se movilizan de maneras más o menos organizadas, en ocasiones individualmente y en otras bajo experiencias de organización colectiva, ante la persecución y las prácticas violentas de las cuales son objeto.

En contraste con los vendedores porteños, en el caso de los camelôs con los que realicé mi trabajo de campo, la defensa de su actividad en tanto su "derecho a trabajar" no aparecía como un horizonte legítimo de reclamo bajo su condición de camelôs. Es que, a diferencia de los vendedores porteños, mis interlocutores brasileños de Estação Central no parecían percibir su actividad como un "trabajo", no, al menos, en los mismos términos que los vendedores porteños.

Respecto al valor del "trabajo" presente en el imaginario social brasileño, éste se vincula con el particular contexto histórico y político de Brasil. Dice Kathleen M. Millar (2014) que "a diferencia de otros sitios latinoamericanos, más notablemente Argentina (Perelman 2007), la imagen del trabajador no siempre ha funcionado como una fuente primaria de identidad y ciudadanía” (MILLAR, 2014, p. 40). Fue en la época de la presidencia de Getúlio Vargas cuando “el 
trabajo se valorizó por primera vez en la historia de Brasil", ya que previo a ese momento, "la historia de la esclavitud en Brasil y el poder continuo de la oligarquía después de la abolición en 1888", habían producido "el efecto de desvalorizar el trabajo manual” (p. 40). Con las reformas laborales de Vargas y la creación de la carteira assinada, "los trabajadores lograron acceder a derechos en función de su trabajo", pero, al mismo tiempo, "quienes no estaban empleados en profesiones legalmente reguladas fueron excluidos de este nuevo status de ciudadanía" (p. 40). De esta manera, señala Millar (2014), "al exaltar al 'trabajador' como ciudadano modelo", quedó establecida la dicotomía "trabajador/ criminal" que sigue operando en "el orden moral de la sociedad brasilera" (p. 41). Dicotomía que más recientemente se ha complejizado, en un contexto en el que "el simbolismo de 'trabajador' ha adquirido un significado adicional en el contexto del narcotráfico, la violencia y el miedo al crimen entre las clases medias y altas en las principales ciudades de Brasil.” (p. 41). Esto es, en vez de asociar a los habitantes de las favelas con "los pobres de la clase trabajadora, las élites perciben cada vez más a los residentes de las favelas como marginales, una palabra que ahora significa criminales y narcotraficantes en lugar de los más pobres de los pobres (PERELMAN 2010, p. 157; ROTH-GORDON 2009, p. 58)" (p. 41). En este sentido, se comprende la categorización difundida en el sentido común brasileño que opone "trabalhadores" y "bandidos" (ZALUAR, 1994; FELTRAN, 2007, 2010). Según Gabriel de Santis Feltran (2007), en las esferas social y pública, esta "categorização bipolar entre 'trabalhadores' e 'bandidos", plástica y variable según el contexto en el que se formula, "define nada menos que o acesso ao 'direito a ter direitos'(ARENDT 2000, p. 330), elemento central na conformação do mundo público" (FELTRAN, 2007, p. 26) . "Esta nomeação define, então, quem pode e quem não pode estabelecer-se como sujeito nos espaços públicos, e quem são os adversários a serem reprimidos.” (FELTRAN, 2007, p. 26).

Entonces, de aquel contexto brasileño de la Presidencia de Vargas de derechos sociales y protección estatal hacia los trabajadores formalmente empleados, el empleo formal y estable devino en "un valor social dominante" (MILLAR, 2014, p. 34). Así, la adquisición de un trabajo formal conlleva "el status de un trabalhador respetado, un trabajador" (p. 34). De la mano de esta valorización del trabajo formal y de la consecuente bipolarización señalada más arriba, otras actividades quedaron fuertemente estigmatizadas. Tal es el caso de catadores de Río de Janeiro que, siguiendo las investigaciones de Millar (2014), quienes ejercen esa actividad cargan con el estigma de ser "una actividad asociada en el imaginario social más amplio con el crimen, la drogadicción, el alcoholismo y la mendicidad: un estigma que puede acarrear consecuencias violentas" (MILLAR, 2014, p. 42). En esta línea, dicen Mota y Freire (2011) en relación a las representaciones de status de los individuos que circulan en el sistema social (y también legal) 
brasileño, la "atribuição de categorias sociais representadas como moralmente inferiores no espaço público determina, em grande medida, o reconhecimento ou não dos direitos dos indivíduos portadores dessas identidades deterioradas, sendo estes destituídos de dignidade" (MOTA y FREIRE, 2011, p. 143).

Ahora bien, en el caso de quienes se dedican a la actividad de venta ambulante, dice Daniel Hirata (2014), históricamente los vendedores ambulantes "no eran percibidos como trabajadores, sino más bien como un segmento de la población que combinaba merodeadores, desempleados y aquellos que luchaban por sobrevivir." (HIRATA, 2014, p. 98). De aquí que, "la principal forma de interfaz entre ellos y el gobierno se construyó mediante políticas e instrumentos para el mantenimiento del orden público" (p. 98). El autor señala que si bien en las dos primeras décadas del siglo actual, se han producido transformaciones en las formas de tratamiento de los vendedores las cuales implicaron "nuevas regulaciones (que) apuntan a su integración urbana y económica como emprendedores con acceso a facilidades de crédito." (p. 103), dichas acciones solamente afectaron a cierto sector, particularmente a las asociaciones de vendedores de los camelódromos, provocando a la vez una profundización de las políticas de orden público destinadas hacia aquellos que siguieron ejerciendo la venta en la calle y no dejaron de ser "vistos como delincuentes" (p. 103).

Considerando las representaciones de status de los individuos presentes en el imaginario social brasileño, se comprende el hecho de que ser camelô en las calles y sin autorización para hacerlo, sea vivido con cierta resignación; resignación al no poder liberarse de lo que es percibido como un estigma, según mis interlocutores. En el caso de los camelôs, la realización de su actividad parecía concebirse más como una "necesidad" para la supervivencia en tanto su condición de "desempleados" que como un "trabajo". Es que, para mis interlocutores, "trabajar" implicaría contar con un empleo con carteira assinada, lo cual da cuenta de una valorización del trabajo formal en contraposición a su actividad como camelôs. De aquí expresiones como la de Jorge, vendedor en la calle con nueve años de antigüedad, que al preguntarle si no aspiraba a conseguir una licencia para tener una barraca habilitada, me contestó que no, que para él era "la misma cosa". Su idea, era más bien, si en un futuro lo lograba, abrir una tienda para poder "dejar de ser camelô".

Teniendo en cuenta las valoraciones de los camelôs sobre su actividad, es posible entender la mayor resignación que encontré entre los mismos frente a las formas de tratamiento que recibían por parte de los guardias e incluso la tolerancia ante determinadas prácticas violentas, como señalé en el apartado anterior. Es que, a diferencia de los vendedores porteños que perciben su actividad como un "trabajo" y desde allí defienden su "derecho a trabajar", pareciera 
que entre mis interlocutores camelôs, primaba una cierta resignación (PIRES, 2010, p. 387) a “ubicarse en su lugar", en términos de Roberto DaMatta (1997), es decir, una mayor incorporación de la relación de desigualdad en la que se encuentran y de la violencia que conlleva, por sobre la demanda de derechos.

\section{CONSIDERACIONES ABIERTAS}

En este escrito intenté dar cuenta de algunas reflexiones que me suscitaron los contrastes que fui encontrando entre los vendedores callejeros de uno y otro lugar, en la medida que desenvolvía mi trabajo de campo entre los camelôs de Estação Central. Así, esta experiencia me permitió repensar aspectos que hacían a los valores y a las obligaciones morales que se ponían en juego en las dinámicas de interacción establecidas entre los vendedores y los agentes de control de ambos espacios. Asimismo, a partir de las reacciones y las expresiones que encontré entre los camelôs, reflexioné acerca de la legitimidad/ilegitimidad de las prácticas de los agentes estatales desde las perspectivas de los vendedores y, en relación con eso, acerca de las identificaciones de los vendedores sobre su actividad y las percepciones sobre sus derechos en vinculación con los imaginarios sociales en los que se hallan inmersos. Lejos de pretender realizar reflexiones acabadas, en este artículo atiné a postular que, en el caso porteño, los vendedores reclaman sus derechos partiendo de la identificación de su actividad como un "trabajo", en tanto forma digna y legítima de integración social. Mientras que, en el caso de los camelôs, las valoraciones que hacen sobre su actividad dan cuenta de su representación como una necesidad de supervivencia, la cual es percibida además como una actividad estigmatizada y, en consecuencia, quienes la realizan, como sujetos sin "derecho a tener derechos". Así se explica la presencia de una mayor sumisión o resignación ante prácticas de control y represión que entre los vendedores porteños no son toleradas.

Ahora bien, mi intención con este trabajo no es atribuirles una identidad homogénea ni a los vendedores porteños, ni a los camelôs de Río de Janeiro. Considero más bien que los sentidos atribuidos a la actividad de venta callejera dependen de las perspectivas y de las situaciones en que las clasificaciones son formuladas (FELTRAN, 2010), así como de las temporalidades de los procesos sociales (PERELMAN, 2017). Con esto quiero remarcar que las interpretaciones sobre los camelôs que postulé en este trabajo refieren particularmente a mis indagaciones etnográficas con mis interlocutores de Estação Central. Por lo mismo, no quisiera sostener que 
no existan reacciones, organización o demanda de derechos entre los camelôs de Río de Janeiro, de hecho son varias las experiencias de organizaciones de camelôs en la ciudad que establecen luchas por sus derechos . Asimismo, tampoco sería adecuado postular que todos los vendedores porteños entienden su actividad como un "trabajo". A lo sumo, podría decir que las reflexiones hechas en este artículo y las comparaciones que aborda, se limitan a dos grupos de vendedores de una y otra ciudad, que comparten ciertas características en común; se trata de vendedores que ejercen su actividad en la calle y que no cuentan con autorización para hacerlo.

En definitiva, lejos de buscar hacer grandes generalizaciones, el objetivo fue aquí menos pretencioso. A través de la comparación por contraste, busqué contribuir al entendimiento de las "complejidades y heterogeneidades en el mundo popular y en relación al trabajo" (PERELMAN, 2017, p. 85), lo cual implica necesariamente alejarse de una única concepción abstracta de lo que la actividad significa para los sujetos para, entonces, adentrarse a la manera en la que los sujetos viven (PERELMAN, 2011, p.72).

\section{REFERENCIAS}

1. CARDOSO DE OLIVEIRA, Luis Roberto. Racismo, direitos e cidadania. Estudos avançados, São Paulo, v. 18, n. 50, 81-93, 2004. Disponível em: https://www.scielo.br/ pdf/ea/v18n50/a09v1850.pdf. Acesso em: 15 dez. 2018.

2. CARDOSO DE OLIVEIRA, Luis Roberto. Honra, dignidade e reciprocidade. In: MARTINS, P. H.; NUNES B. (Org.). A nova ordem social: perspectivas da solidariedade contemporânea. Brasil: Paralelo 15, 2004a.

3. CARDOSO DE OLIVEIRA, Luis Roberto. Direitos, insulto e cidadania: existe violência sem agressão moral? Série Antropología, Brasília, n. 371, 2005. Disponível em: http:// dan.unb.br/dan-producaocientifica/serieantropologia. Acesso em: 20 dez. 2018.

4. DAMATTA, Roberto. Sabe com quem está falando? Um ensaio sobre a distinção entre indivíduo e pessoa no Brasil. In: DAMATTA, Roberto. Carnavais, malandros e heróis: para uma sociologia do dilema brasileiro. Río de Janeiro, Brasil: Rocco, 1997.

5. FASSIN, Didier. On Resentment and Ressentiment: The Politics and Ethics of Moral Emotions. Current Anthropology, Chicago, 54, n.3, p. 249-267, 2013. Disponível em: https://www.jstor.org/stable/10.1086/670390. Acesso em: 02 fev. 2019. 
6. FELTRAN, Gabriel de Santis. Periferias, direito e diferença: notas de uma etnografia urbana. Revista de Antropologia, São Paulo, v. 53, n. 2, p. 565-610, 2010. Disponível em: https://www.revistas.usp.br/ra/article/view/37711. Acesso em: 20 dez. 2018.

7. FELTRAN, Gabriel de Santis. Trabalhadores e bandidos: categorias de nomeação, significados políticos. Tematicas, v. 15, n. 30, p 11- 50, 2007. Disponível em: https:// econtents.bc.unicamp.br/inpec/index.php/tematicas/article/view/13649. Acesso em: 20 dez. 2018.

8. FERNÁNDEZ ÁLVAREZ, Maria Inés. "En defensa de la fuente de trabajo": demandas y prácticas de movilización en una empresa recuperada de Buenos Aires. Avá, Revista de Antropología, Posadas, n. 11, p. 63-85, 2007. Disponível em: https://www.redalyc. org/pdf/1690/169014141003.pdf. Acesso em: 15 dez. 2020.

9. FERNÁNDEZ ÁLVAREZ, María Inés. Más allá de la precariedad: prácticas colectivas y subjetividades políticas desde la economía popular argentina. Íconos: Revista de Ciencias Sociales, Quito, n. 62, p. 21-38, 2018. Disponível em: https://revistas. flacsoandes.edu.ec/iconos/article/view/3243. Acesso em: 15 jan. 2019.

10. HIRATA, Daniel. Street commerce as a 'problem' in the cities of Rio de Janeiro and São Paulo. Vibrant: Virtual Brazilian Anthropology, Brasília v. 11, n. 1, p. 96-117, 2014. Disponível em: https://www.scielo.br/scielo.php?script=sci_ arttext\&pid=S1809-43412014000100004. Acesso em: 15 jan. 2019.

11. MILLAR, Kathleen M. The precarious present: Wageless labor and disrupted life in Rio de Janeiro, Brazil. Cultural Anthropology, Virgínia, v. 29, n. 1, p. 32-53, 2014. Disponível em: https://www.researchgate.net/publication/261107398_The_Precarious_ Present_Wageless_Labor_and_Disrupted_Life_in_Rio_De_Janeiro_Brazil. Acesso em: 02 fev. 2019.

12. MOTA, Fabio Reis; FREIRE, Leticia de Luna. O direito de ter ou não direitos: a dimensão moral do reconhecimento na promoção da cidadania. Contemporânea - Revista de Sociologia da UFSCar, São Carlos, v. 1, n. 1, p. 127, 2011. Disponível em:https://app. uff.br/riuff/bitstream/1/6563/1/O\%20direito\%20de $\% 20$ ter $\% 20$ ou $\% 20$ n $\%$ C3\%A3o $\% 20$ direitos\%20-\%20Fabio\%20Mota.pdf. Acesso em: 02 fev. 2019.

13. PACECCA, María Inés; CANELO, Brenda; BELCIC, Sofía. Culpar a los negros y a los pobres. Los "manteros" senegaleses ante los allanamientos en el barrio de Once. In: PITA, María Victoria; PACECCA, María Inés (Ed.). Territorios de control policial. 
Gestión de ilegalismos en la Ciudad de Buenos Aires. Buenos Aires: Editorial de la FFyL-UBA, 2017.

14. PERELMAN, Mariano Daniel. La construcción de la idea de trabajo digno en los cirujas de la ciudad de Buenos Aires. Intersecciones en Antropología, Buenos Aires, n. 12, p. 69-81, 2011. Disponível em: https://www.redalyc.org/pdf/1795/179522601006.pdf. Acesso em: 02 fev. 2019.

15. PERELMAN, Mariano Daniel. Trabajar, pedir, vender. El caso de los vendedores ambulantes en trenes de la Ciudad de Buenos Aires, Argentina. The Journal of Latin American and Caribbean Anthropology, v. 18, n. 2, p. 231-250, 2013. Disponível em: https://ri.conicet.gov.ar/handle/11336/27463. Acesso em: 15 dez. 2018.

16. PITA, María Victoria. Poder de policía y administración de grupos sociales. El caso de los vendedores ambulantes senegaleses en la Ciudad Autónoma de Buenos Aires. In: PITA, María Victoria; PACECCA, María Inés (Ed.). Territorios de control policial. Gestión de ilegalismos en la Ciudad de Buenos Aires. Buenos Aires: Editorial de la FFyL-UBA, 2017.

17. PITA, María Victoria; PACECCA, María Inés (Eds.), Territorios de control policial. Gestión de ilegalismos en la Ciudad de Buenos Aires. Buenos Aires: Editorial de la FFyL-UBA, 2017.

18. PIRES, Lenin. Arreglar não é pedir arrego. Uma etnografia de processo de administração institucional de conflitos no âmbito da venda ambulante em Buenos Aires e Rio de Janeiro. 2010. Tese (Doutorado em Antropologia) - Programa de Pós-Graduação em Antropologia, Universidade Federal Fluminense, Niterói.

19. PIRES, Lenin. Esculhamba, mas não esculacha. Um relato sobre os usos dos trens urbanos da Central do Brasil, no Rio de Janeiro, enfatizando as práticas de comerciantes ambulantes e conflitos existentes entre estes e outros atores, naquele espaço social. 2005. Dissertação (Mestrado em Antropologia) - Programa de Pós-Graduação em Antropologia, Universidade Federal Fluminense, Niterói.

20. RIBEIRO, Gustavo Lins. Descotidianizar. Extrañamiento y conciencia práctica. Un ensayo sobre la perspectiva antropológica. Cuadernos de antropología social, Buenos Aires, n. 3, p. 65- 69, 1989. Disponível em: http://revistascientificas.filo.uba.ar/index. php/CAS/article/view/4852. Acesso em: 02 fev. 2019. 
21.ZALUAR, Alba. A máquina e a revolta: as organizações populares e o significado da pobreza. Brasil: Brasilense, 1985.

Sofía Belcic

Profesora en Ciencias Antropológicas en la Universidad de Buenos Aires. Becaria doctoral del Consejo Nacional de Investigaciones Científicas y Técnicas con sede de trabajo en la Sección de Antropología Social del Instituto en Ciencias Antropológicas. ID ORCID: https://orcid. org/0000-0001-8813-0640. E-mail: sofiabelcic@yahoo.com.ar. 